\section{International Overdose Awareness Day - August 31, 2016}

August 31 is International Overdose Awareness Day, a global event that aims to raise awareness that overdose death is preventable. Goals include providing awareness regarding the risk for overdose, providing information on community services, and preventing and reducing drugrelated harm by supporting evidence-based policy and practice (http://www.overdoseday.com).

In 2015, the Drug Enforcement Administration and CDC released alerts identifying illicitly manufactured fentanyl as a threat to public health and safety $(1,2)$. Although fentanyl is available as a prescription medication for treating severe pain, including cancer-related pain, the current epidemic of synthetic opioid-involved overdose deaths largely involves illicitly manufactured fentanyl that is mixed with or sold as heroin $(1,3)$.

In contrast to the 2005-2007 fentanyl overdose outbreak, when deaths were confined to several states, the current epidemic is unprecedented in scope and, as described in a report in this issue of $M M W R$, multiple states in several regions of the United States are reporting substantial increases in fatal synthetic opioid-involved overdoses, primarily driven by fentanyl-involved overdose deaths. Further information and data about fentanyl from CDC are available at http://www. cdc.gov/drugoverdose/opioids/fentanyl.html.

\section{References}

1. Drug Enforcement Administration. DEA issues nationwide alert on fentanyl as threat to health and public safety. Washington, DC: US Department of Justice, Drug Enforcement Administration; 2015. http://www.dea.gov/divisions/hq/2015/hq031815.shtml

2. CDC. CDC Health Advisory: increases in fentanyl drug confiscations and fentanyl-related overdose fatalities. Atlanta, GA: US Department of Health and Human Services, CDC; 2015. http://emergency.cdc. gov/han/han00384.asp

3. Drug Enforcement Administration. National heroin threat assessment summary - updated. DEA intelligence report. Washington, DC: US Department of Justice, Drug Enforcement Administration; 2016. https://www.dea.gov/divisions/hq/2016/hq062716_attach.pdf

\section{Fentanyl Law Enforcement Submissions and Increases in Synthetic Opioid-Involved Overdose Deaths - 27 States, 2013-2014}

R. Matthew Gladden, $\mathrm{PhD}^{1}$; Pedro Martinez, $\mathrm{MPH}^{1}$; Puja Seth, $\mathrm{PhD}^{1}$

In March and October 2015, the Drug Enforcement Administration (DEA) and CDC, respectively, issued nationwide alerts identifying illicitly manufactured fentanyl (IMF) as a threat to public health and safety $(1,2)$. IMF is unlawfully produced fentanyl, obtained through

\begin{abstract}
INSIDE
844 Increases in Fentanyl-Related Overdose Deaths Florida and Ohio, 2013-2015

850 National, Regional, State, and Selected Local Area Vaccination Coverage Among Adolescents Aged 13-17 Years — United States, 2015

859 Fractional-Dose Inactivated Poliovirus Vaccine Immunization Campaign — Telangana State, India, June 2016

864 Vital Signs: Epidemiology of Sepsis: Prevalence of Health Care Factors and Opportunities for Prevention

870 Update: Interim Guidance for the Evaluation and Management of Infants with Possible Congenital Zika Virus Infection — United States, August 2016

879 Notes from the Field: Outbreak of Listeriosis Associated with Consumption of Packaged Salad United States and Canada, 2015-2016

882 Notes from the Field: Cluster of Tuberculosis Cases Among Marshallese Persons Residing in Arkansas -

884 QuickStats
\end{abstract}

Continuing Education examination available at http://www.cdc.gov/mmwr/cme/conted_info.html\#weekly.

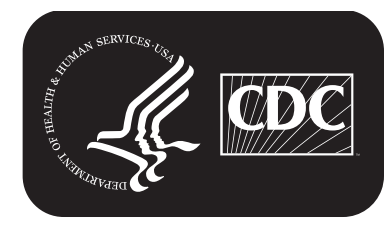

U.S. Department of Health and Human Services Centers for Disease Control and Prevention 